\title{
Pinpoint Loading Examinations of Poly(lactic acid) Biopolymers
}

\author{
L. Kotrocz, P. Bakonyi \\ Budapest University of Technology and Economics, Department of Polymer \\ Engineering \\ Muegyetem rkp. 3., 1111Budapest, Hungary \\ e-mail: bakonyi@pt.bme.hu
}

Abstract: We have made a new mounting unit for Dynamic Mechanical Analysis (DMA) equipment, suitable for measuring microhardness and indentation, and examined its usability on thermoplastic poly(lactic acid) (PLA) material. We used a Vickers-type microhardness indenter, and examined the dimensions of the indented area and the loading force. This novel unit is suitable for measuring the short and long-term behavior of the material using pinpoint load not only at room temperature $\left(20-23{ }^{\circ} \mathrm{C}\right)$ - like common hardness tests - but at a wide range of temperatures.

Keywords: poly(lactic acid); biopolymer; pinpoint load; Vickers indentation; Dynamic Mechanical Analysis

\section{Introduction}

As technology develops, polymers are more and more widely used. In some cases, they can replace metals, due to their adequate strength, low density, good corrosion resistance and vibration damping ability, but they can behave very differently compared to metals. In the case of polymers it is not enough to examine quasi-static mechanical characteristics (tensile and flexural tests) because they react to long-term loading with continuously increasing deformation; this is called creeping. Therefore, it is an important rule for designers that they should design parts not for lifetime but for maximal possible deformation. Creep is most widely determined with tensile and flexural tests, but torsion and compression loading is also used. Compression loading can be area or pinpoint loading. In this paper we studied the latter one [1]. 
Nowadays, with the advancement of the environment-conscious approach, more and more research is directed at the recycling of plastics and the development of biopolymers. Biopolymers can replace petroleum-based polymers in many cases. Perhaps the most well-known of these is Poly(lactic acid) (PLA). It is used in many areas, such as packaging, foams, textiles (geotextiles, towels) and even medical applications. PLA is mechanically excellent with an elastic modulus of 3000-4000 $\mathrm{MPa}$ and a tensile strength of 50-70 MPa, but it's brittle; its tensile elongation is around 3-5\% and its impact strength is low. It can be processed with conventional technologies. PLA composites and nanocomposites are used more and more. Fiber or nanoscale fillers can modify the different properties of PLA [2-6].

Pinpoint compression loading can be examined very well with a hardness test. The hardness of materials is an important characteristic that helps designers select the right material. It is defined as the resistance of a solid material to penetration by a body. Depth-sensitive hardness testing (depth-sensing indentation - DSI) was developed while the advantages of hardness testing were retained. During this process, the measuring body is pushed into the surface at constant speed or with a constant force, and then removed. The geometry of the impression depends on the depth of indentation, which in turn depends on the loading force, and the time of loading, and of course, environmental parameters, such as humidity and temperature. Various characteristics can be determined from it, such as dynamic hardness, conventional hardness, modulus of elasticity, and elastoplastic mechanical properties [7-8].

The advantage of depth-sensing indentation is that measurements can be made in the millimeter, micrometer and nanometer range as well. This facilitates the testing of various thin films, or new materials produced by nanotechnology (e.g. nanocomposites), even with very little loading forces (in the case of nanohardness testing, it can be $0.01 \mathrm{mN}$ ). This procedure may be suitable for the testing of products made of PLA [4-5]. A disadvantage is that the measurement results are always local, and can be very different. Also, there are two important phenomena to be mentioned. Next to the indenter, at the side of the indented area, the surface can sink (sinkingin), or can be raised because material is pushed out (pilling-up), and these can cause inaccuracies (Fig. 1). For this reason, several tests have to be performed for accurate results [7]. 


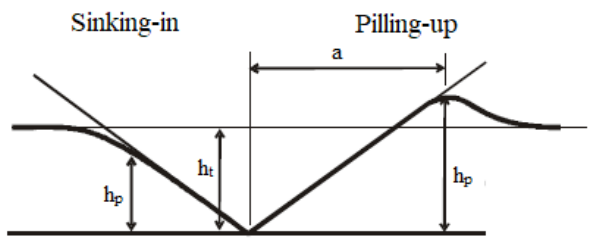

Effective contact surface

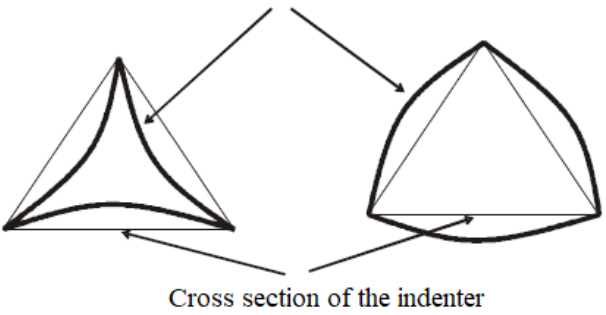

Figure 1. Sinking-in and pilling-up [2]

According to the literature we analyzed, [9-11] this procedure, combined with creep tests, is used successfully on polymer materials. The indenters were mostly Vickers- or Berkovich-type indenters. Usually, finite element analysis is performed as well, to support the measurement results.

The literature [9-11] shows that although this method is spreading, tests are performed almost exclusively at room temperature. However, polymer objects can behave differently at other temperatures and humidity; therefore we decided that tests should be performed in a wide range of temperatures. In order to provide the small loading forces and constant temperature required for the test, we designed a mounting unit suitable for pinpoint loading. In a dynamic mechanical analyzer (DMA), short, long and also cyclical tests can be performed with the unit.

\section{Methods and Materials}

\subsection{The mounting unit designed}

We designed the mounting unit for a TA Instruments (USA) Q800 device. The analyzer can perform various tests (tensile, compression, flexural and shear tests) in a wide temperature range $\left(-145^{\circ} \mathrm{C}\right.$ to $\left.+600{ }^{\circ} \mathrm{C}\right)$, and it has a frequency range of 0.01 $\mathrm{Hz}$ to $200 \mathrm{~Hz}$. Both constant and periodic loading can be applied up to $18 \mathrm{~N}$. The device can determine the mechanical and viscoelastic properties of various materials [12]. 
We designed the mounting unit based on an existing fixture used for compression tests. We had two concepts, one where the indenter is fastened in the middle of the fixture, and another called the "horse race track" design (this allows the positioning of the indenter). Fig. 2 shows the two designs.

a)

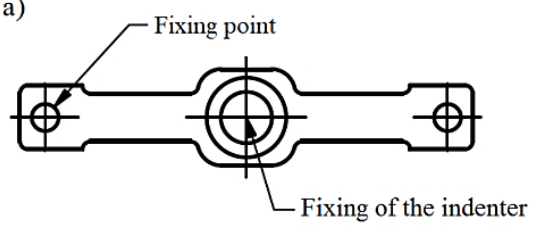

b)

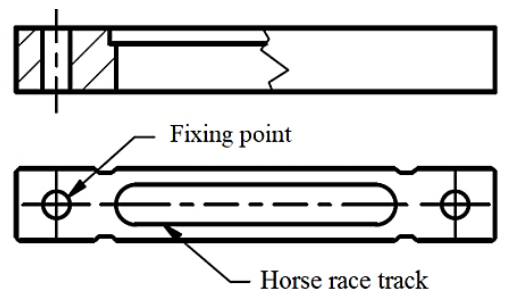

Figure 2. Designs of the fixture, fixed (a) and "horse race track" (b) design

We tested the two concepts with finite element analysis at room temperature to see what deformations occur. Fig. 3 shows that in the case of the horse race track design, in an extreme position, at a load of $18 \mathrm{~N}$, the frame deforms as well, which can damage the air bearing system of the DMA and the mounting unit itself, especially if deformation resulting from temperature change is also taken into account, because at higher temperatures the deformations can be bigger. The asymmetric load caused by the indenter in the extreme position can occasion buckling of the 150-200 mm long and $1 / 4$ inch diameter spindle supported by the air bearing. The spindle is fixed at its lower end and extends beyond the air bearing about $80-100 \mathrm{~mm}$, therefore the deformation of the whole system is more than what is shown. Therefore, we selected as the final design, the centrally positioned, gripped indenter design to avoid asymmetric loading. 

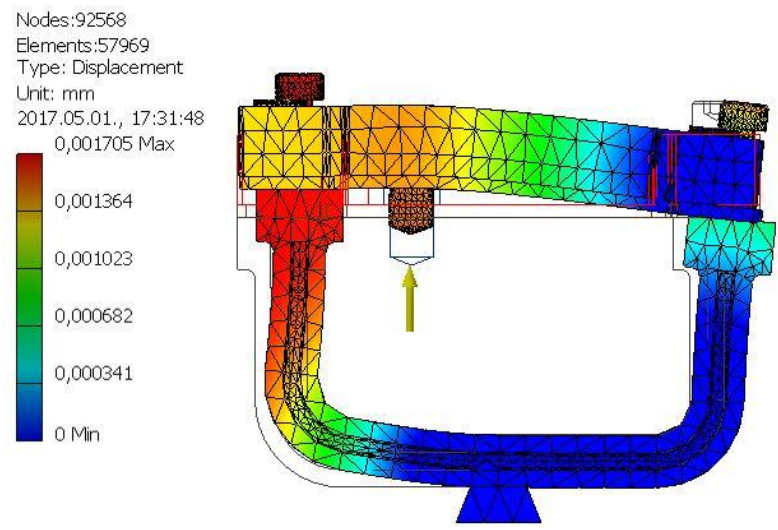

Figure 3. The finite element simulation results of the horse race track in an extreme position

We made the sample holder so that the sample can be positioned. This makes it possible to perform several measurements on a single sample. Thanks to the vice design, the specimen can be tightly gripped and so it does not move during the test. The final design manufactured from ST32 stainless steel can be seen in Fig. 4.

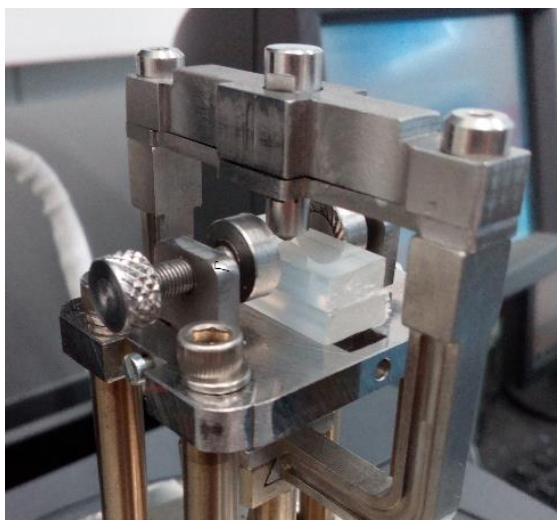

Figure 4. The designed fixture and the gripped PLA specimen

\subsection{The test program and the investigated material}

We tested 3100 HP from NatureWorks (Minnetonka, MN, USA) PLA, whose Dlactide content $(0.5 \%)$ was provided by the manufacturer. The granules were dried at $80{ }^{\circ} \mathrm{C}$ for 6 hours prior to processing to remove residual moisture and thus to avoid 
hydrolitical degradation during processing. ISO 527-2 type 1A standard dumbbellshaped specimens were injection molded with an Arburg Allrounder 370S 700-290 injection molding machine (Lossburg, Germany) equipped with a $30 \mathrm{~mm}$ diameter, $\mathrm{L} / \mathrm{D}=25 \mathrm{screw}$. Injection rate was $50 \mathrm{~cm}^{3} / \mathrm{s}$, holding pressure was 600 bars, holding time was $20 \mathrm{sec}$, residual cooling time was $40 \mathrm{sec}$, and melt and mold temperature were $190^{\circ} \mathrm{C}$ and $25^{\circ} \mathrm{C}$, respectively.

The specimens were cut out from the injection molded dumbbells and their dimensions were $10 \mathrm{~mm} \times 20 \mathrm{~mm}$ x $4 \mathrm{~mm}$. We performed the test on the $10 \mathrm{~mm} \times$ $20 \mathrm{~mm}$ surface, which was the polished surface of the mold. We increased loading force $(\mathrm{F}[\mathrm{N}])$ from $3 \mathrm{~N}$ to $15 \mathrm{~N}$, by $3 \mathrm{~N}$ in each step. The loading time was $30 \mathrm{~s}, 60$ $\mathrm{s}$ and $90 \mathrm{~s}$. The temperature was $35^{\circ} \mathrm{C}$ in every case. In the tests, we used a Vickers microhardness indenter, which is pyramid-shaped and is made of diamond. This geometry reduces dependence on loading force. The parameters measured on the negative mark of the indenter can be seen in Fig. 5, where $a$ and $b$ are the side length, $d_{1}$ and $d_{2}$ are the diagonals and $h$ is the cone height of the Vickers intender.
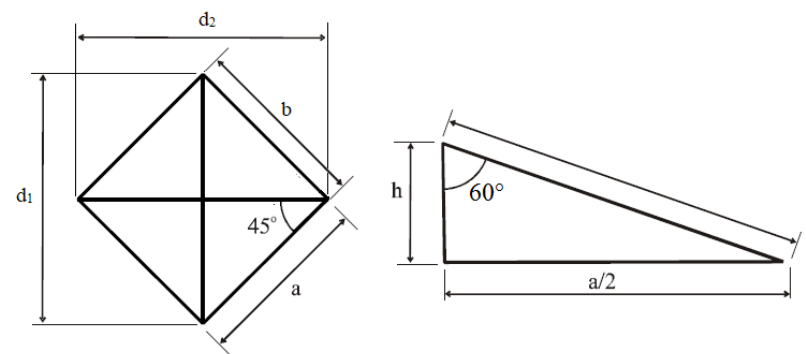

Figure 5. The impression of a Vickers indenter and its geometrical parameters [7]

The testing program consisted of the following steps: we heated the heat chamber to $35^{\circ} \mathrm{C}$, and held this temperature for 3 minutes. Then we applied the loading force. After loading ceased, we analysed the indented area with an optical microscope (Olympus BX51M, Japan), and measured the diagonals of the indented areas $\left(d_{1}, d_{2}\right.$ $[\mu \mathrm{m}])$.

\section{Results and discussion}

As mentioned above, evaluation started with the microscopy examination of the indented areas. We experienced pilling-up and sinking in several cases during the tests; an example is shown in Fig 6. 

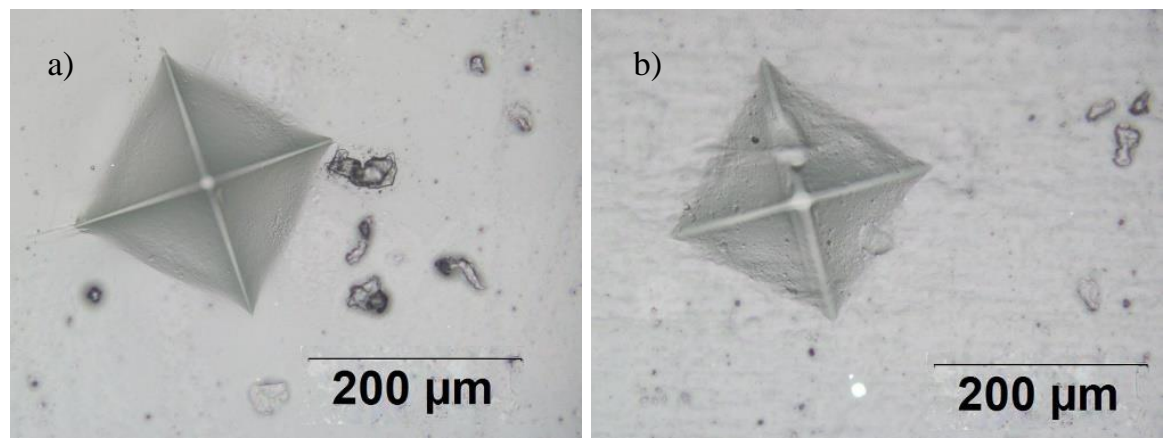

Figure 6. Pilling-up (a) and sinking-in (b) phenomena on the PLA material

We measured the diagonals of the impressions. The diagonal length-force curve for the 30-second loading time test is displayed in Fig. 7.

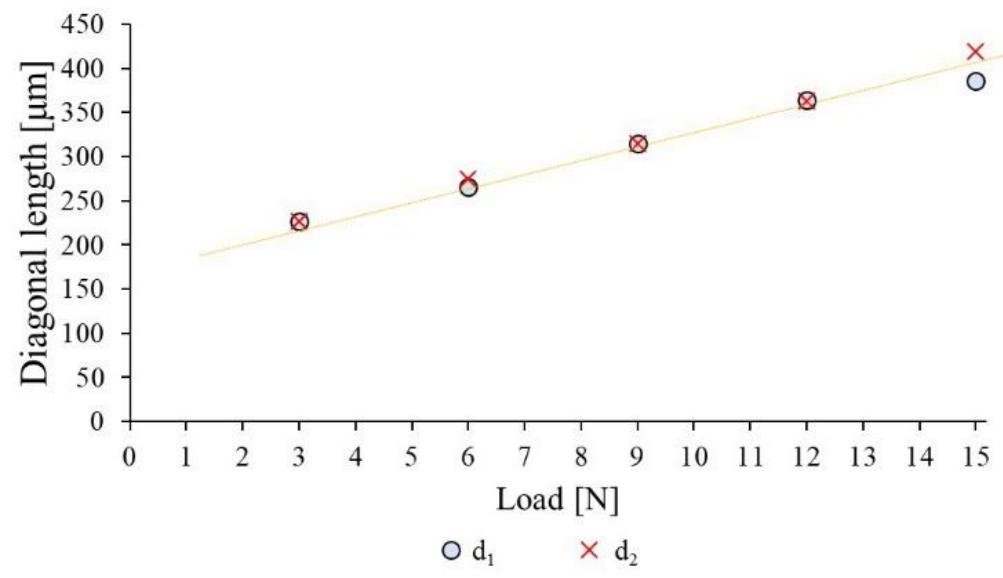

Figure 7. The diagonals as a function of loading force, in the case of $30 \mathrm{~s}$ loading time

It is visible that the points are on one line with little deviation. This proves that the impressions are symmetrical; therefore, the fixture can be used in indentation tests in a DMA. Because of the symmetry, the diagonals can be averaged. In Fig. 8. we displayed the averaged diagonals as a function of loading, in the case of different loading times. 


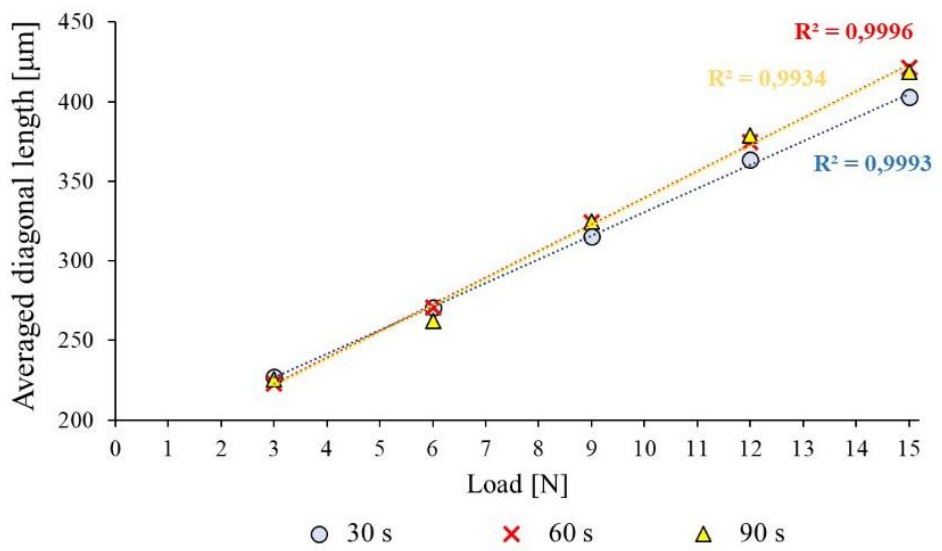

Figure 8. Averaged diagonal length as function of loading force

If the diagonals are known, the projected area $\left(A\left[\mu \mathrm{m}^{2}\right]\right)$ of the pyramid created by the indenter can be calculated with equation (1), and its change can be plotted as a function of the force (Fig. 9).

$$
A=\frac{d_{1} \cdot d_{2}}{2}\left[\mu m^{2}\right]
$$

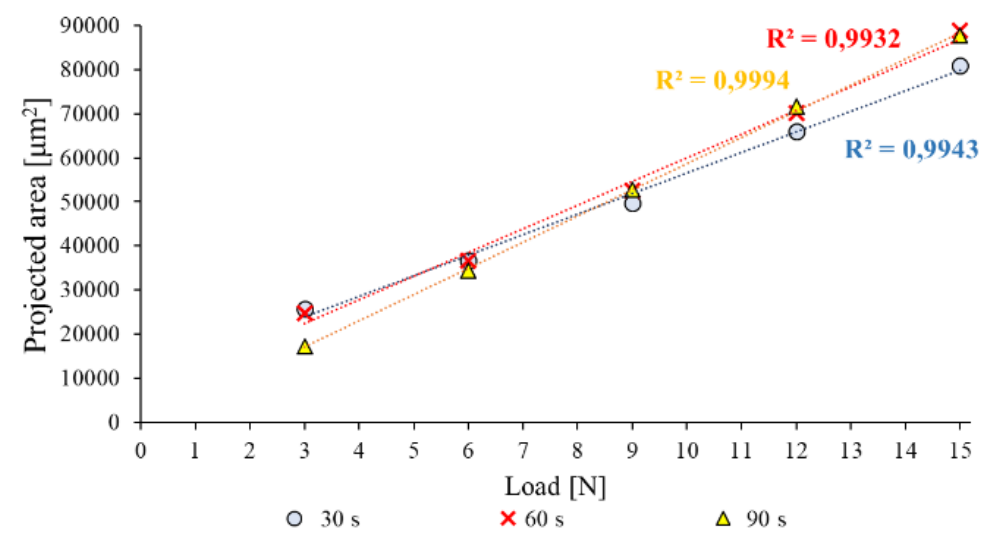

Figure 9. Projected area as a function of loading force

From the measured diagonals, the depth of the impression can be calculated with equation (2): 


$$
h=\frac{\mathrm{d}}{2 \cdot \sqrt{2} \cdot \tan \left(\frac{\theta}{2}\right)},
$$

where $h[\mu \mathrm{m}]$ is the depth of the indent, $d[\mu \mathrm{m}]$ is the average length of the diagonal and $\theta[\mathrm{rad}]$ is the angle of the indenter $\left(136^{\circ}\right)$. Its change can also be displayed as a function of the force (Fig. 10.).

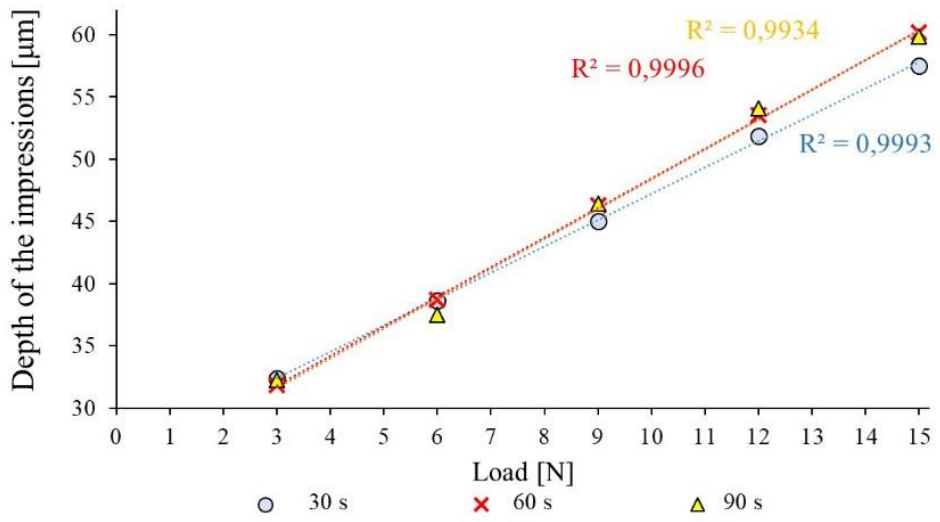

Figure 10. Depth of the impression as a function of loading force (enlarged)

With the method of least squares, we can align linear trend lines for the points in each case. The lines all have a determination coefficient above 99\%. All of the diagrams demonstrate that longer loading times result in deeper and bigger impressions.

The diagrams show that larger force resulted in larger impressions. Also, if loading time was longer, it also resulted in larger impressions. There is no significant difference between $60 \mathrm{~s}$ and $90 \mathrm{~s}$ results at this temperature. Therefore, in the future, it is enough to do one of the measurements, or study that at another temperature.

The diagonal sizes were measured as soon as possible (within 30 seconds), but it should be noted that the time and temperature dependence of diagonal and depth recovery requires additional tests, because there is instantaneous recovery due to the momentary elastic deformation component, which is typical for polymers, along with delayed elastic and irreversible components [13].

From the calculated results, in the future, we can determine the hardness of the material, and also other mechanical properties, such as elastic modulus. 


\section{Conclusions}

The tests showed that the fixture we designed is suitable for pinpoint loading tests with DMA equipment. This method can be used for the mechanical testing of the surface of polymer products. We can calculate the projected area and the depth of the impressions, which we can use to determine the hardness of the measured material. Also, in the future, we can compare the data calculated from the optical microscopy images with the indentation depths measured with the DMA device. Therefore, we will be able to examine the phenomenon of creep, and the impressions need not be measured with an optical microscope.

Thanks to the DMA equipment, the procedure can be used not only for static tests but also dynamic and cyclic tests. In addition, tests can be performed in a wide range of temperatures. In the case of longer tests, creep has to be expected, which is characteristic to polymers. In smaller sizes, creep can be more pronounced; therefore more detailed tests need to be done regarding this.

\section{Acknowledgements}

The project is funded by the National Research, Development and Innovation (NKFIH) Fund, Project title: "Developing a new generation of customized medical implants and medical aids for additive technologies"; The application ID number: NVKP_16-1-2016-0022. The developers are grateful for the support.

\section{References}

[1] J.S. Urzumtsev, R.D. Maksimov, Deformation of plastics. Prognostics on the basis of similarity principles, 1st edition, Müszaki Könyvkiadó, Budapest, 1982.

[2] Poly(lactic acid): Synthesis, Structures, Properties, Processing, and Applications, in: R. Auras, L. T. Lim, S. E. M. Selke, H. Tsuji (Eds), 1st Edition, John Wiley \& Sons, Inc., Hoboken, New Jersey, 2010. doi: $10.1002 / 9780470649848$

[3] S. Shankar, J.W. Rhim, Polymer Nanocomposites for food packaging Applications, in: A. Dasari, J. Njuguna (Eds), Functional and Physical Properties of Polymer Nanocomposites, John Wiley \& Sons, Inc., Hoboken, New Jersey, 2016, pp. 29-55. doi: $\underline{10.1002 / 9781118542316 . \operatorname{ch} 3}$ 
[4] S. C. Cifuentes, E. Frutos, R. Benavente, V. Lorenzo, J. L. GonzálezCarrasco, Assessment of mechanical behavior of PLA composites reinforced with $\mathrm{Mg}$ miceo-particles through depth-sensing indentations analysis, Journal of the mechanical behavior of biomedical materials, 65 (2017) pp. 781-790. doi: 10.1016/j.jmbbm.2016.09.013

[5] S.C. Cifuentes, E. Frutos, R. Benavente, J.L. González-Carrasco, V. Lorenzo, Strain rate effect on semi-crystalline PLLA mechanical properties measured by instrumented indentation tests, 59 (2014) pp. 239-246.

doi: 10.1016/j.eurpolymj.2014.07.034

[6] S. Hajba, T. Tábi, Investigation of long cellulose fibre reinforced and injection moulded poly(lactic acid) biocomposites, Acta Technica Jauriensis, 11 (3) (2018) pp. 150-164.

doi: 10.14513/actatechjaur.v11.n3.469

[7] P. M. Nagy, Investigation of block and surface mechanical properties of structural polymers by indentation measurement technologies, $\mathrm{PhD}$ thesis, Eötvös Lóránd University (2007).

[8] J. Gubicza, A. Juhász, J. Lendvai, A new method for hardness determination from depth sensing indentation test, Journal of Materials Research, 11 (12) (1996) 2964-2967.

doi: $10.1557 / J M R .1996 .0376$

[9] P. J. Wei, W. X. Shen, J. F. Lin, Analysis and modeling for time-dependent behavior of polymers exhibited in nanoindentation tests, Journal of NonCrystalline Solids, 354 (33) (2008) pp. 3911-3918. doi: 10.1016/j.jnoncrysol.2008.05.016

[10] R. Seltzer, Y.-W. Mai, Depth sensing indentation of linear viscoelastic-plastic solids: A simple method to determine creep compliance, Engineering Fracture Mechanics, 75 (17) (2008) pp. 4852-4862. doi: $\underline{10.1016 / \text { j.engfracmech.2008.06.012 }}$

[11] K. Altaf, I. A. Ashcroft, R. Hague, Modelling the effect of moisture on the depth sensing indentation response of a stereolithography polymer, Computational Materials Science, 52 (1) (2012) pp. 112-117. doi: 10.1016/j.commatsci.2011.01.051 
L. Kotrocz and P. Bakonyi - Acta Technica Jaurinensis, Vol. 11, No. 4, pp. 206-217, 2018

[12] TA Instruments, DMA Q800 user manual (2011) [cited 2017-10-12].

URL http://www.tainstruments.com/wp-content/uploads/dma.pdf

[13] R. J. Crawford: Microhardness testing of plastics, Polymer Testing, 3 (1) (1982) pp. 37-42.

doi: $\underline{10.1016 / 0142-9418(82) 90011-3}$ 